\title{
The role of atmospheric ions in aerosol nucleation - a review
}

\author{
M. B. Enghoff and H. Svensmark \\ National Space Institute, Technical University of Denmark, Copenhagen, Denmark \\ Received: 12 February 2008 - Published in Atmos. Chem. Phys. Discuss.: 17 April 2008 \\ Revised: 14 July 2008 - Accepted: 1 August 2008 - Published: 27 August 2008
}

\begin{abstract}
Atmospheric aerosols affect climate and yet the reason for many observed events of new aerosol formation is not understood. One of the theories put forward to explain these events is that the presence of ions can enhance the formation of aerosols. The theory is called Ion Induced Nucleation and in this paper the state of observations, theory and experiments within the field will be reviewed. While evidence for Ion Induced Nucleation is accumulating the exact mechanism is still not known and more research is required to understand and quantify the effect.
\end{abstract}

\section{Introduction}

Aerosols are present throughout the atmosphere and affect Earth's climate directly through backscattering of sunlight and indirectly by altering cloud properties (Forster et al., 2007). However the exact mechanism controlling the early stages of aerosol formation is still not understood. Several measurements of atmospheric nucleation have been reported where the observed nucleation rates cannot be explained by the traditional theory of binary homogeneous nucleation by water and sulphuric acid (Hoppel et al., 1994; Weber et al., 1996; Weber et al., 1997; Clarke et al., 1998; O’Dowd et al., 1999; Weber et al., 2001a; Birmili et al., 2003). A ternary nucleating agent such as ammonia has been proposed to enhance the nucleation process by stabilising early cluster formation (Weber et al., 1996; O’Dowd et al., 1999; Weber et al., 1998; Kulmala et al., 2000). Another possibility is that ions, produced mainly by galactic cosmic rays, can explain the observed nucleation rates (Turco et al., 1998).

In 1895 it was shown for the first time that ionising radiation in the form of $\mathrm{x}$-rays has an impact on the nucleation of particles in the gas phase (Wilson, 1895). Using an expansion chamber the Scottish scientist Wilson noted that the amount of droplets formed was greatly enhanced when the

Correspondence to: M. B. Enghoff (enghoff@space.dtu.dk) experiment was exposed to X-rays. Later the experiment was repeated with radiation from Uranium with the same result and it was concluded that the droplets were formed on ions (Wilson, 1899). With time other experiments have shown similar effects under conditions with extreme gas compositions or ionisation levels (Megaw and Wiffen, 1961; Bricard et al., 1968; Vohra et al., 1984; Raes et al., 1985; Rabeony and Mirabel, 1987; Adachi et al., 1992; Kim et al., 1997), and in normal atmospheric conditions (Svensmark et al., 2007).

Dickinson (1975) speculated on how ions can influence aerosol nucleation and clouds; later Arnold (1980) suggested that multi ion complexes can serve as condensation nuclei in the stratosphere, and Turco et al. (1998) argued that the recombination of ions could nucleate aerosols. In 1997 the role of ionisation from galactic cosmic rays was linked with cloud formation based on satellite observations of clouds and ground based cosmic ray measurements (Svensmark and Friis-Christensen, 1997; Marsh and Svensmark, 2003). A similar connection was later discovered by Harrison and Stephenson (2006) for the UK. Udelhofen and Cess (2001) found that cloud cover in the United States for the last 100 years correlated with solar activity, meaning that it anticorrelated with galactic cosmic rays, i.e. the opposite correlation than what was found globally and for the UK. Kazil et al. (2006) modelled the response in cloud cover forced by cosmic ray changes but found no significant effect.

Since the amount of atmospheric ions is changing on timescales of hours to millennia a connection between ions and clouds could result in corresponding changes to aerosol and cloud properties which would be important for understanding past and even future climate changes.

In this paper the role of ions in aerosol nucleation will be reviewed - for a more general review of aerosol nucleation see the book by Seinfeld and Pandis (1998, Chap. 10) or the recent paper by Curtius (2006). Three areas: Observations, Theory and Experiments will be described in separate sections. Observations (Sect. 2) covers all measurements performed in the atmosphere from studies of the general behaviour of ions to particle nucleation observations where the role of ions is considered. In Sect. (3): Theory, the various

Published by Copernicus Publications on behalf of the European Geosciences Union. 
equations and models applied to understanding nucleation via ions are presented, and the Experiments section (Sect. 4) describes laboratory measurements from nucleation events to investigations of single reactions. Finally the state of the field will be summarised (Sect. 5).

\section{Observations}

There are numerous studies where atmospheric nucleation rates are reported. A review paper by Kulmala et al. (2004b) lists more than 100 individual investigations several of which report nucleation rates unexplainable by the standard theory of binary homogeneous nucleation. An analysis by Yu et al. (2008) showed that most of these observations could be described by nucleation by ions (see Sect. 3). Studies where the role of ions is investigated are somewhat more sparse and apply varying methods. However they can be roughly divided into two types - those that solely investigate the behaviour of the ions and those where the development of ions is studied together with nucleation events.

\subsection{Ions}

An introduction to ion chemistry in the atmosphere has been written by Ferguson et al. (1979, Chap. 2), and Viggiano (1993) has made a description of the instrumentation used for measuring atmospheric ions. A review of atmospheric ion formation and different mechanisms for nucleation via ions was given by Harrison (2000).

Large positive cluster ions (mass $\leq 2500 \mathrm{amu}$ ) were detected in the upper troposphere for the first time in 2002 (Eichkorn et al., 2002) using a large ion mass spectrometer. The most common ions measured were composed of water, acetone, and a proton. Two larger modes were also detected. The lesser of these could be explained by the uptake of sulphuric acid but there were insufficient amounts of condensable gases to explain the largest measured particles by any other means than attachment of small aerosols to the ion clusters. The required concentration of these aerosols was $2.5 \cdot 10^{4} \mathrm{~cm}^{-3}$ and their presence could not be explained by homogeneous nucleation, which strongly indicated that the ions participated in the formation. Even larger ions with a mass up to $8500 \mathrm{amu}$ were detected directly in the exhaust of a jet aeroplane (Eichkorn et al., 2002). These ions were found to participate in the formation of larger aerosols and might evolve into cloud condensation nuclei (Yu and Turco, 1999).

Many years of work on ions in the free troposphere and stratosphere was summarised by Arnold (2006), and major cluster ions were reported containing sulphuric acid, nitric acid, acetone, water and acetonitrile. Arnold concluded that nucleation via ions, henceforth referred to as ion induced nucleation (INU) can occur in the upper troposphere and that the freshly nucleated particles can be transported either downwards to serve as cloud condensation nuclei or upwards to the stratospheric aerosol layer (the Junge Layer).

Hõrrak et al. (1998a) described how the measurement of ion mobility in air can be used to determine the size of the ion. That technique has recently been used to detect a preexisting distribution of neutral aerosols below the limit of detection by conventional aerosol sizing techniques - the measurement was achieved by first ionising the neutral particles and then measuring the mobility of the resulting ions (Kulmala et al., 2007). Hõrrak et al. (1998b) used an air ion spectrometer to measure bursts of intermediate ions with mobilities from 0.034 to $0.5 \mathrm{~cm}^{2} \mathrm{~V}^{-1} \mathrm{~s}^{-1}$ corresponding to sizes of 1.6 to $7.4 \mathrm{~nm}$ at Takhuse, Estonia. These bursts could either be explained by a) attachment of ions to homogeneously nucleated particles or b) INU. The observed bursts were however smaller than what would be expected for homogeneous nucleation.

The ion production rate $Q$ is a key parameter for any theory of INU since it will determine the amount of ions available for nucleation. Laakso et al. (2004b) compared two methods of estimating $Q: 1$ ) Direct measurement of ionisation sources (Radon, galactic cosmic rays and gamma radiation from the ground); and 2) Measuring the distributions of small ions and particles and then solving Eq. (1) for $Q$ assuming steady-state.

$$
\begin{aligned}
& \frac{d n_{ \pm}}{d t}=Q-\alpha n_{ \pm}^{2} \\
& -n_{ \pm} \int_{d_{p}} \sum_{q=-\infty}^{\infty} \beta_{ \pm}\left(d_{p}, q\right) N\left(d_{p}, q\right) d d_{p}
\end{aligned}
$$

where the second term in Eq. (1) is the loss of ions by recombination and the third term corresponds to the attachment of small ions to aerosols. $n_{ \pm}$is the concentration of either negative or positive ions (assumed to be equal), $\alpha$ is the ionion recombination coefficient, $d_{p}$ is the aerosol diameter, $q$ the charge of the aerosol particle, $\beta_{ \pm}\left(d_{p}, q\right)$ the ion-aerosol attachment coefficient and $N\left(d_{p}, q\right)$ the aerosol concentration. Since the recombination and attachment coefficients are known, and the concentrations of ions and aerosols measured, it is possible to estimate $Q$. This method did, however, underestimate the ion production rate somewhat compared to the direct method (2.6 ion pairs $\mathrm{cm}^{-3} \mathrm{~s}^{-1}$ vs 4.5 ion pairs $\mathrm{cm}^{-3} \mathrm{~s}^{-1}$ for the conditions in this setup), possibly due to the lack of information about aerosol particles smaller than $3 \mathrm{~nm}$. The measurements were taken during the QUEST campaign in a forest at Hyytiälä, Finland, just above ground level. The research station at Hyytiälä was described by Hari and Kulmala (2005). In a later paper by Hõrrak et al. (2008), it was discovered that, for the method of measuring ion and particle distributions, it was necessary to include an extra loss term. This term corresponds to the deposition of small ions onto the forest, and including it brings the calculated ionisation rate more in line with the direct measurement. 


\subsection{Nucleation}

The QUEST campaign also produced a set of simultaneous measurements of aerosol and ion concentrations along with the trace gases sulphuric acid and ammonia (Laakso et al., 2004a). The particles formed during a nucleation event were overcharged with negative ions indicating the participation of negative ion chemistry in the nucleation process. However little change in the number of small cluster ions (stable ions with a diameter of $\sim 1.5 \mathrm{~nm}$ ) was observed during the events, contrary to what would be expected from INU. This was possibly due to mixing of air parcels or a decrease in the ion condensation sink to other particles previous to the events. Modelling of the observed events indicated that they could be explained mainly by nucleation of sulphuric acid and ammonia with subsequent growth via sulphuric acid and organics and that the ions played a secondary role. A later and more detailed analysis (Vana et al., 2006) divided the observed nucleations events into strong and weak events based on the amount of nucleated particles, and it was shown by analysis of the charged fraction that ions played the largest role in the weak nucleation events.

Three years of simultaneous ion and particle measurements were reported by Hirsikko et al. (2007a). Ions with sizes from 0.42 to $7 \mathrm{~nm}$ were measured along with particles above $3 \mathrm{~nm}$. Each day of measurements were classified as an event, undefined, or non-event day $-26 \%$ of the days were event days for negative ions while there were $22 \%$ event days for positive ions. Neutral aerosols were also measured. 286 event days were measured in total for neutral particles, and 229 of these were also event days with regards to ions (negative or positive). It was also found that intermediate ions (with sizes from $\sim 1.6 \mathrm{~nm}$ to $7 \mathrm{~nm}$ ) appeared during rain- and snowfall possibly due to the breakup of water droplets and the presence of ice crystals, respectively.

In an earlier study from 2001 (Harrison and Aplin, 2001) an attempt was made to directly observe the effect of ions on condensation nuclei in a field study near Reading, England. Two separate Geiger counters were used to identify periods of cosmic ray showers and separate them from other more local ionisation events. A Gerdien counter (Aplin and Harrion, 2000; Gerdien, 1905) measured the negative ions, and aerosols were measured simultaneously. During a 1-hour period with many cosmic ray shower events a positive correlation $(r=0.5456)$ was seen between the negative ions and the rate of change in aerosols. If the aerosols were produced by other means than INU (e.g. particles nucleated by another mechanism elsewhere and transported to the sampling site by advection) a decrease in small ions measured by the Gerdien would be expected from Eq. (1) whereas an INU event is characterised by an increase in ionisation followed by an increase in particle concentration. During the same period the aerosol amount did not correlate with wind speed, further indicating that advection did not interfere.
Another series of ground level observations was carried out from March to September 2004, and May to October 2005, near Boulder, Colorado USA (Iida et al., 2006). Aerosol size distributions were measured from $3 \mathrm{~nm}$ to $5 \mu \mathrm{m}$ using a nano- and a regular Scanning Mobility Particle Sizer (SMPS) and an optical particle counter. In addition the mobility of ions corresponding to a size range of 0.4 to $6.3 \mathrm{~nm}$ was recorded using a mobility analyser. By operating the nano-SMPS in two modes, with and without the air passing through a charger, it was possible to determine the fraction of charged particles. This was double-checked by comparison with the ratio of ions as measured by the mobility analyser to the total particle number from the nano-SMPS in the overlapping size-region. A theoretical analysis showed that for the measured particle growth rates the charged fraction of nucleated particles would retain their original charge. Since most nucleation events showed charged fractions below the expected steady state values it was concluded that INU was not contributing significantly to nucleation. However, a few events showed charge imbalances (mostly with increased negative charge) which could only be explained by INU. A quantitative study showed that the average contribution of INU was about $0.5 \%$.

Laakso et al. (2007) developed an instrument to measure the charged fraction of particles in nucleation events. Particles were passed through a charger that could be turned on and off, and the size distribution was then determined by a differential mobility particle sizer with a switchable polarity to measure either positive or negative ions. Thirty-four particle nucleation events from Hyytiälä forest, Finland, were analysed, and a charged fraction above the expected equilibrium was detected in many cases indicating a contribution from INU. Negative overcharging was more commmon than positive. It was concluded that INU took place but that neutral nucleation was dominant on most days. That INU is not dominant on this measurement location is also supported by Kulmala et al. (2007). These conclusions are however undergoing debate due to uncertainty in the interpretation of the overcharge of the measured particles (Yu et al., 2007a,b).

Looking at measurements from the same site Kulmala et al. (2004a) discovered that the growth rate of aerosols between 1.5 and $20 \mathrm{~nm}$ increases with size. This could be due to the activation of organic vapours meaning that when these are present INU is not dominating for the growth of the aerosol but can still be important for nucleation. The activation theory can also explain observations where the nucleation of new clusters depend on the concentration of sulphuric acid to the power of one (Kulmala et al., 2006).

Charged fractions were also measured at three sites in the Baltic Sea region (Komppula et al., 2007), but these indicated that INU was not a major contributor to the observed nucleation events. Simultaneous measurements of ions and particles have additionally been made by the same group at such diverse locations as indoors/outdoors in urban Helsinki (Hirsikko et al., 2007b), along a roadside (Tiitta et al., 2007), 


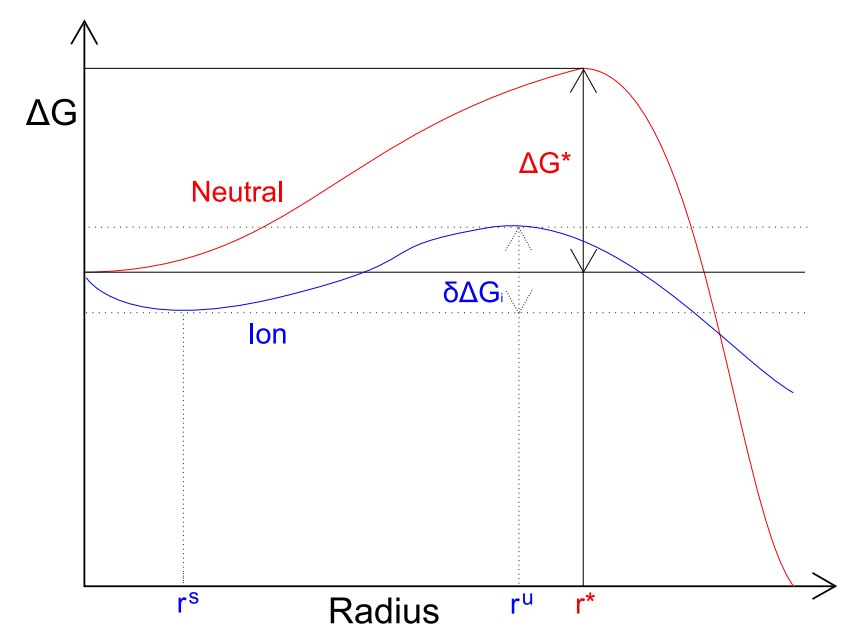

Fig. 1. Energy barriers: The red line depicts the Gibbs free energy of a neutral cluster as a function of size. The blue line corresponds to a cluster containing an ion. Adapted from Curtius et al. (2006).

in a cloud (Lihavainen et al., 2007), along the Trans-Siberian rail road (Vartiainen et al., 2007) and in Antarctica (Virkkula et al., 2007). A special issue of "Boreal Environment Research" was dedicated to air ions and aerosols, dealing with, amongst others, the papers mentioned in this paragraph (Kulmala and Tammet, 2007).

Observations in the upper atmosphere are more rare but one set was provided by Lee et al. (2003) who carried out 56 aircraft flights from 7 to $21 \mathrm{~km}$ at latitudes between $10^{\circ} \mathrm{N}$ to $90^{\circ} \mathrm{N}$, measuring particle size distributions between 4 and $2000 \mathrm{~nm}$ as well as $\mathrm{OH}$ and $\mathrm{SO}_{2}$ concentrations. Backward trajectory calculations supplied information on exposure of the air parcel to sunlight. The data was analysed using a thermodynamic model for INU (Lovejoy et al., 2004) - the model will be described in the Theory section. Two case studies of high and low particle concentrations were presented and modelled succesfully by the INU model.

The observational studies approach INU from different angles, and the interpretations are, in some cases, still undergoing debate. Techniques to quantify the importance of INU in observations exist but are still under development. The difficulty in observing clusters smaller than $3 \mathrm{~nm}$ is one of the challenges for truly understanding the nucleation. The new instrument, described by Kulmala et al. (2007), which is based on the principle of ionising neutral particles and detecting them like ions, could be a great step towards solving this problem. Another challenge is that the exact mechanism for INU is not yet known: thus it is difficult to point out which parameters are most important to measure and how to interpret them. One approach to solving this problem is by theoretical analysis, and the next section summarises the various theories and models in the field.

\section{Theory}

Nucleation is basically a competition between the growth and evaporation of molecular clusters. For a stable cluster to be formed an initial energy barrier must be overcome - this barrier is due to the surface tension of the cluster. The height of this barrier is determined by the temperature and concentration of the nucleating species. There are several good introductions to nucleation theory (Seinfeld and Pandis, 1998, Chap. 10); (Curtius, 2006). This section will deal with how the addition of an electrical charge alters the nucleation process.

\subsection{Thermodynamic theory}

The classical approach to bi-molecular homogeneous nucleation uses thermodynamics, where the standard nucleation rate $J$ (new particles formed per volume per time unit) is given as:

$J=C e^{\frac{-\Delta G^{*}}{k T}}$

where $\Delta G^{*}$ is the free energy of formation of the critical cluster (the required cluster size to overcome the energy barrier), $k$ Boltzmann's constant, $T$ the temperature, and $C$ the pre-exponential factor that can be calculated in various ways, see (Reiss, 1950) for the original derivation or e.g. Hamill et al. (1982)

$C=4 \pi r^{* 2} \beta_{a} N_{b}$

where $r^{*}$ is the radius of the critical cluster. In the case of bi-molecular homogeneous nucleation $a$ molecules condense onto $b$ molecules. $\beta_{a}$ is thus the collision rate of $a$ molecules per unit area (this could be sulphuric acid molecules) and $N_{b}$ is the concentration of $b$ molecules (this could be water). The dependency of $\Delta G$ on the particle radius can be seen as the red curve in Fig. 1; $\Delta G^{*}$ is the height of the barrier.

The introduction of an ion does, however, change this as a stable equilibrium state $\left(r^{s}\right)$ is introduced prior to the barrier, see the blue curve in Fig. 1. The result is that the energy needed to nucleate is the difference between that of the stable equilibrium $\left(r^{s}\right)$ and that of the unstable where the $\Delta G$ function is at a maximum $\left(r^{u}\right)$. Equation (2) is thus changed into:

$J=C e^{\frac{-\delta \Delta G_{i}}{k T}}$

where $r^{*}$ in Eq. (3) is changed into $r^{u}$ (the critical radius for the ion cluster) and $N_{b}$ to $N_{i}$, the ion concentration. $\Delta \mathrm{G}_{i}$ is smaller than $\Delta G^{*}$ due to the contribution to the free energy of the electrostatic attraction the ion exerts on the cluster.

For the classical determination of $r^{u}, r^{s}$ and $\Delta G_{i}$ see the work by Yue (1979). Fisenko et al. (2005) investigated 
the effect of the dipole moment on $\delta \Delta G_{i}$ and also considered possible explanations for sign preference. Nadykto and $\mathrm{Yu}$ (2004) discussed the modelling of the dipole further, and their calculations compared well with experimental nucleation measurements. Thomsons's charged liquid drop model, employed in the determination of $\delta \Delta G_{i}$, was tested experimentally for various clusters (Holland and Castlemann Jr., 1982) with a positive core ion. The results compared favourably for water clusters but not for the other ligands tested. Modifications to the model were discussed but these did not resolve the discrepancies. Yu (2005) proposed a modified Thomson model taking into account the interaction between the core ion and the ligand dipoles. For small clusters (with the number of ligands being below 6) the modified theory provided good results for the ligands $\mathrm{H}_{2} \mathrm{O}, \mathrm{NH}_{3}, \mathrm{CH}_{3} \mathrm{OH}$ and $\mathrm{C}_{5} \mathrm{H}_{5} \mathrm{~N}$. The core ion was $\mathrm{H}^{+}$in all cases.

It is important to note that the maximum in $\Delta G$ only occurs when the gas-phase is saturated with regard to the nucleating compounds, and at sufficiently high supersaturations the energy barrier can disappear completely. Under conditions where $\delta \Delta G_{i}<\Delta G^{*}$ the ions can cross the smaller barrier for INU, recombine and then continue to grow as a neutral particle. However since $r^{*}$ is always greater than $r^{u}$ it can happen that the ion is neutralised before $r^{*}$ has been passed, thus resulting in the evaporation of the aerosol. Therefore a correction is needed for Eq. (4). One suggested correction is a probability factor $P_{i}$ (Hamill et al., 1982)

$P_{i}(\tau)=e^{-\sqrt{Q \alpha} \tau}$

where $\sqrt{Q \alpha}$ is the inverse of the lifetime of an ion due to recombination, $Q$ is the ion production rate, $\alpha$ the recombination coefficient, and $\tau$ is the required time for an ion to grow to the size $r^{u}$. Based on this equation the authors conclude that INU is negligible in the stratosphere but that nucleation onto stable ion-ion recombination clusters can enhance stratospheric nucleation as suggested by Arnold (1980). Raes and Janssens (1985) argued against this solution and suggested an alternative where the ions were divided into two species: $N_{i, 1}$ which are the ions below $r^{u}$ centered at $r^{s}$ and $N_{i, 2}$ which are the ions between $r^{u}$ and $r^{*}$ :

$J_{i, a}=B P^{\prime}\left(\tau^{\prime}\right)+\frac{K N_{i, 2}^{2}}{2}$

where $B$ is the right hand side of Eq. (4) except $N_{i, 1}$ is substituted for $N_{i}$ and $P^{\prime}\left(\tau^{\prime}\right)$ is the chance that an $N_{i, 2}$ ion is not lost by recombination with another ion nor is scavenged within the time needed to grow from $r^{u}$ to $r^{*}$. The last part of Eq. (6) corresponds to the recombination of two $N_{i, 2}$ ions ( $K$ is the recombination coefficient) which in most cases will result in a cluster larger than $r^{*}$. Using this solution it was shown that for the sulphuric acid-water system there exists an interval of sulphuric acid concentrations where INU will dominate - this interval is below the lower limit of where homogeneous nucleation can take place. At $25^{\circ} \mathrm{C}$ and $75 \%$ relative humidity this interval goes from about $10^{7}$ to $5 \cdot 10^{8}$ molecules of sulphuric acid per cubic centimeter. That INU can occur in conditions where homogeneous nucleation cannot is also indicated by Kiang and Stauffer (1973).

A more elaborate model was developed by Laakso et al. (2002). Here ion nucleation was described in a way similar to the classical approach producing stable clusters at a given size, but the following growth by condensation and coagulation was described in detail. Particle sizes go from 0.5 to $1000 \mathrm{~nm}$ radius divided into 37 bins, 10 of which are below $1 \mathrm{~nm}$ and the remaining increase logarithmically in size from $1 \mathrm{~nm}$ and up. The particles below $10 \mathrm{~nm}$ were divided into three charge categories: $+1,0$ and -1 charge whereas the larger particles could have up to five charges of either sign. A special category for ions smaller than $0.5 \mathrm{~nm}$ was also included. In order to investigate the possibility that nucleation occurs only on negative ions the model was tested with positive nucleation disabled. Similar amounts of particles were observed as when both positive and negative nucleation was allowed due to more sulphuric acid being available and because charged particles were not lost due to recombination with each other but only recombined with smaller ions of the opposite sign. Runs of the model at various temperatures and relative humidities showed that some nucleation events (Hõrrak et al., 1998b; Mäkelä et al., 1997) could be explained quite well by the model while others (O'Dowd et al., 1999; Dal Maso et al., 2002) could not.

\subsection{Kinetic theory}

The advent of modern computers has allowed for a kinetic treatment of nucleation in which every reaction involved can be solved numerically. This method provides detailed descriptions of the size distribution of clusters starting with the gas phase monomers as opposed to the thermodynamic approach where the process leading to nucleation is not considered. For a given cluster four basic things can happen: 1) growth by the condensation of a gas phase monomer onto the cluster; 2) loss of mass by the evaporation of a monomer from the cluster; 3 ) growth by coagulation with another cluster; and 4) loss of the cluster due to scavenging by a larger pre-existing particle. When ions are present charged and neutral species can be treated separately. The standard General Dynamic Equation describing the evolution of neutral clusters can be seen in the book by Seinfeld and Pandis (1998, Chap. 12).

One of the first kinetic models was developed by $\mathrm{Yu}$ and Turco (1998) in order to simulate exhaust plumes from aeroplanes. First, processes were so fast that the thermodynamic solution did not apply and second, the evolution of heat in the plumes resulted in very high ion concentrations. 
Coagulation, condensation and evaporation were treated, and neutral, positive, and negative clusters were examined from $0.56 \mathrm{~nm}$ up to $\mu \mathrm{m}$ sizes, with bin sizes, corresponding to the dry particle volume, increasing stepwise by a set factor. All the parameters used were calculated from theory. The model was adapted to investigate the role of ions, referred to by the authors as Ion Mediated Nucleation, on the atmosphere in general (Yu and Turco, 2001) using the water and sulphuric acid binary nucleation scheme. Specifically it was used to simulate one of the hitherto unexplained nucleation events reported by Clarke et al. (1998) and did so with succes. The sensitivity of aerosol formation to the ion production rate was likewise investigated, and it was concluded that the effect of changing ion production is highest when the ion production and the pre-existing areosol surface are low to begin with and when condensable gas concentrations are high. Furthermore the model was used to study ion mobility spectra by Hõrrak et al. (1998b) and a nucleation event from Idaho Hill, Colorado (Weber et al., 1997), and both cases were simulated with reasonable succes (Yu and Turco, 2000). The main conclusion from the model was that INU is most likely to occur in and above the marine boundary layer.

Lovejoy et al. (2004) took the modelling one step further by including exeperimental measurements of the early steps of ion clustering to overcome the problems theory encounters with small size clusters. Thermodynamics for the attachment of water and sulphuric acid to $\mathrm{HSO}_{4}^{-}\left(\mathrm{H}_{2} \mathrm{SO}_{4}\right)_{\mathrm{x}}\left(\mathrm{H}_{2} \mathrm{O}\right)_{\mathrm{y}}$ for $\mathrm{x} \leq 6$ and $\mathrm{y} \leq 10$ and to $\mathrm{H}^{+}\left(\mathrm{H}_{2} \mathrm{SO}_{4}\right)_{\mathrm{x}}\left(\mathrm{H}_{2} \mathrm{O}\right)_{\mathrm{y}}$ for $\mathrm{x} \leq 4$ and $\mathrm{y} \leq 15$ were measured (Froyd and Lovejoy, 2003a,b) to provide input to the model - for larger clusters the measurements converged to the theoretical results. For the neutral clusters theory was applied with a correction to obtain nucleation rates similar to those from Ball et al. (1999). Positive ions were treated as a single species since negative ions seem to be the most active. Negative ions and neutrals were divided into 60 bins up to a size of $1 \mu \mathrm{m}$. Model runs were compared with a suite of observations and were in agreement with measurements done when $\mathrm{T}<270 \mathrm{~K}$ - they underpredicted nucleation rates at higher temperatures and it was concluded that INU with the sulphuric acid and water system explains nucleations in the remote middle troposphere but generally not in the boundary layer, a conclusion that is contrary to that of Yu and Turco (2001). The results of the model were also described by Curtius et al. (2006). In $2006 \mathrm{Yu}$ (2006a) presented the second generation of the Yu and Turco model (Yu and Turco, 1998) using improved theory for the description of small charged clusters and a new scheme for evaporation taking into account thermodynamic data. The original conclusion that INU of sulphuric acid and water can play a significant part in the lower atmosphere, including the boundary layer, was re-confirmed. Differences between this model and the one by Lovejoy et al. (2004) were mentioned and the model details were further discussed in the corresponding discussion paper (Yu, 2006b). The model (Yu, 2006a) was later incorporated into the GEOS-Chem global chemical transport model, producing a global map of calculated nucleation rates by INU. This was compared with an updated list of land based nucleation events based on the review by Kulmala et al. (2004b) along with nucleation rates reported by ship and aircraft measurements. It was found that most of the observations agreed with the predictions by the model with a few notable exceptions where other mechanisms such as nucleation of iodine species are thought to have dominated.

Molecular reactions can also be approached by ab initio calculations. Structures of $\mathrm{HSO}_{4}^{-}\left(\mathrm{H}_{2} \mathrm{SO}_{4}\right)_{\mathrm{x}}$ (Curtius et al., 2001) and $\mathrm{HSO}_{4}^{-}\left(\mathrm{H}_{2} \mathrm{SO}_{4}\right)_{\mathrm{x}}\left(\mathrm{H}_{2} \mathrm{O}\right)_{\mathrm{y}}$ (Froyd and Lovejoy, 2003a) have been done at the Hartree-Fock level while calculations on the hydration of $\mathrm{HSO}_{4}^{-}$and $\mathrm{H}_{2} \mathrm{SO}_{4}$ have been performed by Kurtén et al. (2007) using high level MøllerPlesset pertubation theory.

\subsection{Other theories}

Tinsley (2000) suggested that the effect of cosmic rays on the global electrical circuit may in turn influence the microphysical processes in clouds, specifically the nucleation of ice particles. Changes in cosmic ray intensity alter the conductivity of the atmosphere and therefore the fair weather current $J_{z}$. Near the edges of clouds a space charge is created that allows aerosols to build up a large amount of like charge without suffering neutralisation. Evaporation of water from these particles results in highly charged particles with a coating of condensable gases. The enhanced charge on the particles allows for rapid coagulation (electro-scavenging) with larger droplets and due to the coating of the charged particles this can result in ice nucleation, changing the properties of the clouds. If $J_{z}$ can influence cloud properties, other effects altering $J_{Z}$ would also play a part and this was also investigated in the study. A more thorough review of this mechanism has been made by Gray et al. (2005).

It was recently proposed that the formation of sulphuric acid could take place in clusters containing ozone, $\mathrm{SO}_{2}$ and water without UV light (Svensmark et al., 2007; Sorokin and Arnold, 2007). In the mechanism proposed by Svensmark et al. molecular oxygen picks up a negative charge, takes up water to form a cluster and then switches with ozone to form $\mathrm{O}_{3}^{-}\left(\mathrm{H}_{2} \mathrm{O}\right)_{\mathrm{n}}$ (Fehsenfeld and Ferguson, 1974). $\mathrm{SO}_{2}$ is then taken up by the cluster and oxidised:

$\mathrm{SO}_{2}+\mathrm{O}_{3}^{-}\left(\mathrm{H}_{2} \mathrm{O}\right)_{\mathrm{n}} \rightarrow \mathrm{SO}_{3}^{-}\left(\mathrm{H}_{2} \mathrm{O}\right)_{\mathrm{n}}+\mathrm{O}_{2}$

Alternatively the oxidation could occur outside of a cluster with subsequent hydration:

$\mathrm{SO}_{2}+\mathrm{O}_{3}^{-} \rightarrow \mathrm{SO}_{3}^{-}+\mathrm{O}_{2} \stackrel{\mathrm{H}_{2} \mathrm{O}}{\rightarrow} \mathrm{SO}_{3}^{-}\left(\mathrm{H}_{2} \mathrm{O}\right)$

Formation of sulphuric acid can then occur inside the cluster:

$\mathrm{SO}_{3}^{-}\left(\mathrm{H}_{2} \mathrm{O}\right)_{\mathrm{n}} \rightarrow \mathrm{H}_{2} \mathrm{SO}_{4}^{-}\left(\mathrm{H}_{2} \mathrm{O}\right)_{\mathrm{n}-1}$ 
Following this the electron in the cluster could be ejected, e.g. due to the release of chemical energy within the cluster and thus become available to repeat the process. This implies that nucleation by the way of ions is not limited by the ion production rate. Instead the limiting factor is the rate of cluster production relative to the loss rate of ions by recombination and scavenging by larger clusters: the number of times a single ion can produce a stable cluster. The mechanism could also proceed by a variety of other pathways several options are listed by Sorokin and Arnold (2007).

\subsubsection{Sign-preference}

The apparent preference of anions for nucleation reported in several studies (Laakso et al., 2004a, 2007; Iida et al., 2006; Wilhelm et al., 2004) has been investigated theoretically. Using a molecule-based approach called Dynamical Nucleation Theory it was concluded that not only the sign of the core ion but also its size plays a part: for instance water prefers a small cation over a large anion (Kathmann et al., 2005). Quantum chemical ab initio calculations applied to the problem showed that the electronic structure of the core ion and its interaction with the intermolecular bonds formed during nucleation determines the effect the core ion has on the cluster formation process. Thus using the sign and size of the ion alone is insufficient to determine its effectiveness as a core ion (Nadykto et al., 2006). These results were further discussed by Kathmann et al. (2007) and Nadykto et al. (2007). At present no calculations on sulphur species are available for comparison which would be interesting from an atmospheric point of view.

\subsubsection{Charged fraction}

In several observations (Vana et al., 2006; Iida et al., 2006; Laakso et al., 2007; Komppula et al., 2007) the charged fraction of the particles are used to evaluate the contribution of INU. Since particles nucleate below the limit of detection the charged fraction may change from the time of nucleation and until detection. Kerminen et al. (2007) described how the charged fraction of a particle population evolves with growth and found that it is dependent on two factors: the cluster ion concentration and the growth rate of the population (corresponding to the amount of condensable gases) such that at high ion concentrations and/or low growth rates the information on the original charging state may be lost when the particles are detected. If the electron can be ejected from a cluster due to the release of e.g. chemical energy as suggested by Svensmark et al. (2007) the charged fraction would also be reduced. Thus care must be taken when using the charged fraction as a tool for analysis.

\section{Experiments}

In order to test the theories and understand what to look for in field studies it is necessary to do experiments under controlled conditions. There are two main approaches to experimental investigation of INU. One approach operates on a macroscopic level trying to determine the influence of ions on bulk nucleation. The second approach is to investigate the molecular reactions taking place in an attempt to understand each step in the mechanism of particle formation.

\subsection{Bulk nucleation}

The first of this kind of experiments are the ones conducted by Wilson $(1895,1899)$ where an expansion chamber was exposed to various kinds of ionising radiation, and an increase in density of the resulting fog was reported. With the advent of particle counters more detailed studies became possible, and the relation between generated particles and radiation doses of alpha rays from ${ }^{220} \mathrm{Rn}$, beta rays, and x-rays were reported (Megaw and Wiffen, 1961) using a Pollak condensation nucleus counter (Metnieks and Pollak, 1959). The doses used were from $\sim 1$ to 15 rads forming ion concentrations orders of magnitude above atmospheric levels, and using this span of doses the particle production rate was increased by more than a factor of 100. A correlation of particle number with $\mathrm{SO}_{2}$ was also reported. Bricard et al. (1968) reported a similar effect in an experiment where the charged fraction of the detectable particles $(>100 \mathrm{~nm})$ was measured by applying an electrical charge to a metal tube placed prior to the particle counter, thus removing charged particles. It was shown that a measureable charged fraction only appeared about 50 min after the injection of ${ }^{220} \mathrm{Rn}$. However the limit of particle detection $(100 \mathrm{~nm})$ was so far above the size at which nucleation happens that the experiment did not reveal much about the mechanism of nucleation.

Later experiments investigated whether ionisation could convert $\mathrm{SO}_{2}$ into sulphate and thus particles. Radon was introduced into a system of air, $\mathrm{SO}_{2}, \mathrm{O}_{3}$ and $\mathrm{C}_{2} \mathrm{H}_{4}$ resulting in four times as many particles as previously (Vohra et al., 1984). Realistic Radon levels $\left(100 \mathrm{pCi} \mathrm{m}^{-3}\right)$ but very high $\mathrm{SO}_{2}$ concentrations ( $300 \mathrm{ppb}$ ) were used. This was investigated further (Raes et al., 1985) in a study where a mixture of $\mathrm{SO}_{2}(500 \mathrm{ppb})$ and $\mathrm{NO}_{2}(15 \mathrm{ppb})$ were exposed to $\mathrm{UV}, \mathrm{UV}+$ $\gamma$-rays, and $\gamma$-rays alone. It was concluded that at the higher dose rates (3.4 to $32 \mu \mathrm{Gy} \mathrm{s}^{-1}$ ) the $\gamma$-rays produced sulphuric acid directly while at lower dose rates INU may have taken place. This means that using extreme radiation levels may cause false positive results since the amounts of sulphuric acid produced directly by radiation will be insignificant at natural radiation levels.

An increase of nucleation rate was likewise observed for carbon tetrachloride, chloroform, o-xylene, methanol, ethanol and water in a thermal diffusion cloud chamber exposed to $\alpha$-radiation (Rabeony and Mirabel, 1987). Using 
an electric field to ensure that only ions of one sign were present in the nucleation zone a preference for negative ions was observed, as well as a strong dependence on the strength of the applied electrical field such that the nucleation rate decreased with increasing field strength. By dividing the chamber into two sections and doing the charge separation and nucleation in separate sections it was possible to investigate the sign-effect with no electrical field present, and it was shown that in this case positive and negative ions increased nucleation by equal amounts. In an older study (Loeb et al., 1938) experiments with substances showing negative, positive and no sign preference were described. That the sign preference is dependent upon the species present is well in line with the theoretical work previously mentioned (Nadykto et al., 2006).

Using $n$-propanol, Winkler et al. (2008) showed enhanced nucleation for charged insoluble, inorganic particles. Particles between 0.9 and $4 \mathrm{~nm}$ were studied and a negative signpreference was shown.

Another nucleation experiment was performed by Kim et al. (1997). Nucleation of an $\mathrm{SO}_{2} / \mathrm{H}_{2} \mathrm{O} / \mathrm{N}_{2}$ mixture was initiated by exposure to an ${ }^{241} \mathrm{Am} \alpha$-source producing both ions and $\mathrm{OH}$-radicals. The charged fraction of particles was measured with a CPC (TSI model 3025) by applying a voltage to the collector leading to the CPC thus removing charged particles. With no added $\mathrm{SO}_{2}$ the charged fraction was found to be 1, indicating INU and as $\mathrm{SO}_{2}$ was added the charged fraction decreased as homogeneous nucleation started to play a part. For this system a negative sign-preference was found by two methods. Firstly the charged fractions were examined and secondly the electrical mobility distributions for positive and negative particles revealed a stronger activation by negative ions. In later work by the same group (Kim et al., 1998) the presence of $\mathrm{NH}_{3}$ was found to enhance particle formation and decrease the charged fraction.

Some interesting nucleation results have been obtained by Berndt et al. $(2005,2006)$. Using a flow tube they observed nucleation in the sulphuric acid/water system. $\mathrm{OH}-$ concentrations were inferred from observed loss-rates of otherwise non-interfering organic species and then used to calculate the sulphuric acid concentration. When the sulphuric acid was generated by evaporation from a liquid reservoir the limit for nucleation was above $10^{10} \mathrm{~cm}^{-3}$ which is in line with observations by other investigators (Ball et al., 1999; Wyslouzil et al., 1991; Viisanen et al., 1997). However when the sulphuric acid was generated in situ by photolysis of ozone and subsequent oxidation of $\mathrm{SO}_{2}$ the limit was found to be around $10^{7} \mathrm{~cm}^{-3}$ which corresponds to atmospheric levels (Kazil et al., 2006; Weber et al., 2001b). No explanation for this low limit for nucleation was given, but INU as well as ternary nucleation was ruled out, the former due to the lack of a significant charged particle fraction. Sorokin and Arnold (2007) argued, by considering the time required for aerosol growth in the flow tube, that the sulphuric acid concentration must have been larger in the experiment (around $\left.7 \cdot 10^{8} \mathrm{~cm}^{-3}\right)$.

An experiment in a $7 \mathrm{~m}^{3}$ reaction chamber (Svensmark et al., 2007) showed a linear correlation between nucleated particles and ions for the $\mathrm{H}_{2} \mathrm{O}-\mathrm{H}_{2} \mathrm{SO}_{4}$ system. Sulphuric acid was produced by photolysis at atmospheric levels of $\mathrm{SO}_{2}(\leq 230 \mathrm{ppb}), \mathrm{O}_{3}(\sim 25 \mathrm{ppb})$ and ionisation (10006000 ions $\mathrm{cm}^{-3}$ ) with $\left[\mathrm{H}_{2} \mathrm{SO}_{4}\right] \sim 10^{7}-10^{8} \mathrm{~cm}^{-3}$, showing that INU can happen under atmospheric conditions. By applying an electrical field that reduced the lifetime of a small ion to less than a second the particle production was decreased by up to $50 \%$, suggesting that INU occurs via a process that is fast compared to the recombination time of an ion ( $\sim 200 \mathrm{~s}$ at ground level).

\subsection{Molecular reactions}

By investigating directly the molecules involved in the nucleation process more information about details of the mechanism may be revealed. Castleman Jr. (1982) used a mass spectrometer to investigate the clustering of water, $\mathrm{CO}_{2}$ and $\mathrm{SO}_{2}$ with a large assortment of core ions. Enthalpies, entropies and equilibrium constants were reported. Froyd and Lovejoy investigated the attachment of water to $\mathrm{H}+\left(\mathrm{H}_{2} \mathrm{SO}_{4}\right)_{2}\left(\mathrm{H}_{2} \mathrm{O}\right)_{\mathrm{w}}$ (Froyd and Lovejoy, 2003b) and to $\mathrm{HSO}_{4}^{-}\left(\mathrm{H}_{2} \mathrm{SO}_{4}\right)_{\mathrm{s}}\left(\mathrm{H}_{2 \mathrm{O}}\right)_{\mathrm{w}}$ (Froyd and Lovejoy, 2003a) using mass spectrometry, and the thermodynamics of sulphuric acid ligand bonding to these clusters were calculated. By showing the existence of a thermodynamic barrier for the addition of sulphuric acid to the positive cluster it was concluded that the negative pathway is favoured for the sulphuric acid-water system. The pressure and temperature dependence of the thermal decomposition of $\mathrm{HSO}_{4}^{-}\left(\mathrm{HNO}_{3}\right)_{y}$ and $\mathrm{HSO}_{4}^{-} \mathrm{H}_{2} \mathrm{SO}_{4} \mathrm{HNO}_{3}$ was measured in an ion trap (Curtius et al., 2001). These results were used to verify a master equation for thermal decomposition (Lovejoy and Curtius, 2001).

The evolution of clusters in the sulphuric acid-water system was observed by Wilhelm et al. (2004) in a large ion mass spectrometer. Cluster ions $\mathrm{HSO}_{4}^{-}\left(\mathrm{H}_{2} \mathrm{SO}_{4}\right)_{\mathrm{a}}\left(\mathrm{H}_{2} \mathrm{O}\right)_{\mathrm{w}}$ and $\mathrm{H}^{+}\left(\mathrm{H}_{2} \mathrm{SO}_{4}\right)_{a}\left(\mathrm{H}_{2} \mathrm{O}\right)_{\mathrm{w}}$ were grown with sulphuric acid. It was found that the mole fraction of sulphuric acid approached that of neutral clusters with increasing cluster size. Small negative clusters had more sulphuric acid than neutrals and the small positive clusters had less. The clusters did not grow to the sizes expected from the rate of collision between clusters and sulphuric acid, meaning that detachment of sulphuric acid played an important role. It was also shown that growth was more effective for negative than for positive clusters. A later study using the same setup (Sorokin et al., 2006) determined the hydration constants for the clusters and using the obtained data together with data from Froyd and Lovejoy (2003a) the authors simulated the obtained mass spectra. 


\section{Summary}

Evidence for the importance of ions in aerosol nucleation is accumulating - in this paper we have shown a series of observations, theories and experiments which indicate that INU is a real effect, even under atmospheric conditions. In some studies the effect of ions is seen directly (e.g. Laakso et al., 2004b; Hirsikko et al., 2007a; Iida et al., 2006; Rabeony and Mirabel, 1987; Svensmark et al., 2007), while in others it is a possible explanation, where other options such as ammonia and organics also could be considered (Kulmala et al., 2004a; Lee et al., 2003).

When INU is established as a mechanism for atmospheric nucleation the next question becomes whether the effect is globally important or merely a scientific curiosity. Some of the studies presented here indicate that the contribution from INU is just a few percent, compared to other nucleation mechanisms (Iida et al., 2006; Laakso et al., 2007). On the other hand there are also studies which point to ions as being a dominant source of new particles (Yu et al., 2008). Models also do not agree where in the atmosphere INU can take place (Lovejoy et al., 2004; Yu, 2006a), the main question being whether it can happen in the boundary layer or not, and more data is required to improve the theories.

One major obstacle to overcome in order to quantify the effect of INU is to determine the exact mechanism. It is well established that sulphate species play an important role, however the participation of other compounds cannot be ruled out. The prevailing theory is that ions stabilise the cluster energetically (Lovejoy et al., 2004), but other options such as the introduction of charge-catalysed chemistry is also being considered (Svensmark et al., 2007; Sorokin and Arnold, 2007). The direct observation of nucleating clusters (Kulmala et al., 2007) can potentially provide great insights about the mechanism. Molecular observations and ab initio calculations are other possible approaches.

To quantify the effect it must also be investigated under which conditions the freshly nucleated particles can grow to the size of cloud condensation nuclei, since they risk being scavenged by particles emmited from other sources.

The final step, should INU seem to play a significant role, would be to put the mechanism into the climate models and thus get an estimate of the potential radiative forcing of INU.

Acknowledgements. The authors thank J. O. P. Pedersen, T. Bondo and M. S. Johnson for helpful discussions and comments. We also thank N. Calder and H. Enghoff for proof reading.

Edited by: J. Curtius

\section{References}

Adachi, M., Okuyama, K., and Seinfeld, J. H.: Experimental studies of ion-induced nucleation, J. Aerosol Sci., 23, 327-337, 1992.

Aplin, K. L. and Harrion, R. G.: A computer-controlled Gerdien atmospheric ion counter., Rev. Sci. Instrum., 71, 3037-3041, 2000.

Arnold, F.: Multi-ion complexes in the stratosphere - Implications for trace gases and aerosol, Nature, 284, 610-611, 1980.

Arnold, F.: Atmospheric Aerosol and Cloud Condensation Nuclei Formation: A Possible Influence of Cosmic Rays?, Space Sci. Rev., 125, 169-186, doi:10.1007/s11214-006-9055-4, 2006.

Ball, S. M., Hanson, D. R., Eisele, F. L., and McMurry, P. H.: Laboratory studies of particle nucleation: Initial results for $\mathrm{H}_{2} \mathrm{SO}_{4}$, $\mathrm{H}_{2} \mathrm{O}$, and $\mathrm{NH}_{3}$ vapors, J. Geophys. Res., 104, 23 709-23 718, doi:10.1029/1999JD900411, 1999.

Berndt, T., Böge, O., Stratmann, F., Heintzenberg, J., and Kulmala, M.: Rapid Formation of Sulfuric Acid Particles at Near-Atmospheric Conditions, Science, 307, 698-700, doi:10.1126/science.1104054, 2005.

Berndt, T., Böge, O., and Stratmann, F.: Formation of atmospheric $\mathrm{H}_{2} \mathrm{SO}_{4} / \mathrm{H}_{2} \mathrm{O}$ particles in the absence of organics: A laboratory study, Geophys. Res. Lett., 33, doi:10.1029/2006GL026660, 2006.

Birmili, W., Berresheim, H., Plass-Dülmer, C., Elste, T., Gilge, S., Wiedensohler, A., and Uhrner, U.: The Hohenpeissenberg aerosol formation experiment (HAFEX): a long-term study including size-resolved aerosol, $\mathrm{H}_{2} \mathrm{SO}_{4}, \mathrm{OH}$, and monoterpenes measurements, Atmos. Chem. Phys., 3, 361-376, 2003, http://www.atmos-chem-phys.net/3/361/2003/.

Bricard, J., Billard, F., and Madelaine, G.: Formation and Evolution of Nuclei of Condensation That Appear in Air Initially Free of Aerosols, J. Geophys. Res., 73, 4487-4496, 1968.

Castleman Jr., A. W.: Experimental studies of ion clustering: Relationship to aerosol formation processes and some atmospheric implications, J. Aerosol Sci., 13, 73-85, 1982.

Clarke, A. D. Davis, D., Kapustin, V. N., Eisele, F., Ghen, C., Paluch, I., Lenschow, D., Bandy, A. R., Thornton, D., Moore, K., Mauldin, L., Tanner, D., Litchy, M., Carrol, M. A., Collins, J., and Albercook, G.: Particle nucleation in the tropical boundary layer and its coupling to marine sulfur sources, Science, 282, 89-92, 1998.

Curtius, J.: Nucleation of atmospheric aerosol particles, C. R. Phys., 7, 1027-1045, 2006.

Curtius, J., Froyd, K. D., and Lovejoy, E. R.: Cluster Ion Thermal Decomposition (I): Experimental Kinetics Study and ab Initio Calculations for $\mathrm{HSO}_{4}^{-}\left(\mathrm{H}_{2} \mathrm{SO}_{4}\right)_{\mathrm{x}}\left(\mathrm{HNO}_{3}\right)_{\mathrm{y}}$, J. Phys. Chem. A, 105, 10 867-10 873, 2001.

Curtius, J., Lovejoy, E. R., and Froyd, K. D.: Atmospheric IonInduced Aerosol Nucleation, Space Sci. Rev., 125, 159-167, 2006.

Dal Maso, M., Kulmala, M., Lehtinen, K. E. J., Mäkelä, J. M., Aalto, P., and O'Dowd, C. D.: Condensation and coagulation sinks and formation of nucleation mode particles in coastal and boreal forest boundary layers, J. Geophys. Res. Atmos., 107, 8097-8106, doi:10.1029/2001JD001053, 2002.

Dickinson, R. E.: Solar variability and the lower atmosphere, B. Am. Meteorol. Soc., 56, 1240-1248, 1975. 
Eichkorn, S., Wilhelm, S., Aufmhoff, H., Wohlfrom, K. H., and Arnold, F.: Cosmic ray-induced aerosol-formation: First observational evidence from aircraft-based ion mass spectrometer measurements in the upper troposphere, Geophys. Res. Lett., 29, 43-1, 2002.

Eichkorn, S., Wohlfrom, K. H., Arnold, F., and Busen, R.: Massive positive and negative chemiions in the exhaust of an aircraft jet engine at ground-level: mass distribution measurements and implications for aerosol formation, Atmos. Environ., 36, 18211825, 2002.

Fehsenfeld, F. C. and Ferguson, E. E.: Laboratory studies of negative ion reactions with atmospheric trace constituents, J. Chem. Phys., 61, 3181-3193, 1974.

Ferguson, E. E., Fehsenfeld, F. C., and Albritton, D. L.: Gas Phase Ion Chemistry, 1, Academic Press, 45-82, 1979.

Fisenko, S. P., Kane, D. B., and El-Shall, M. S.: Kinetics of ioninduced nucleation in a vapor-gas mixture, J. Chem. Phys., 123, 104 704-1-104 704-10, doi:10.1063/1.2018632, 2005.

Forster, P., Ramaswamy, V., Artaxo, P., Berntsen, T., Betts, R., Fahey, D. W., Haywood, J., Lean, J., Lowe, D. C., Myhre, G., Nganga, J., Prinn, R., Raga, G., Schulz, M., and Van Dorland, R.: Changes in Atmospheric Constituents and in Radiative Forcing, in: Climate Change 2007: The Physical Science Basis. Contribution of Working Group 1 to the Fourth Assessment Report of the Intergovenrmental Panel on Climate Change, edited by: Solomon, S., Qin, D., Manning, M., Chen, Z., Marquis, M., Averyt, K. B., Tignor, M. and Miller, H. L., Cambridge University Press, 171-180, 2007.

Froyd, K. D. and Lovejoy, E. R.: Experimental Thermodynamics of Cluster ions Composed of $\mathrm{H}_{2} \mathrm{SO}_{4}$ and $\mathrm{H}_{2} \mathrm{O}$. 2. Measurements and ab Initio Structures of Negative Ions, J. Phys. Chem. A, 107, 9812-9824, 2003a.

Froyd, K. D. and Lovejoy, E. R.: Experimental Thermodynamics of Cluster ions Composed of $\mathrm{H}_{2} \mathrm{SO}_{4}$ and $\mathrm{H}_{2} \mathrm{O}$. 1. Positive Ions, J. Phys. Chem. A, 107, 9800-9811, 2003b.

Gerdien, H.: Demonstration eines Apparates zur absoluten Messung der elektrischen Leitfahigheit der Luft, Phys. Zeitung, 6, 800-801, 1905.

Gray, L. J., Haigh, J. D., and Harrison, R. G.: The Influence of Solar Changes on the Earth's Climate, Hadley Centre technical note, 62, 1-81, 2005.

Hamill, P., Turco, R. P., Kiang, C. S., Toon, O. B., and Whitten, R. C.: An analysis of various nucleation mechanisms for sulfate particles in the stratosphere, J. Aerosol Sci., 13, 561-585, 1982.

Hari, P. and Kulmala, M.: Station for Measuring EcosystemAtmosphere Relations (SMEAR II), Boreal Environ. Res., 10, 315-322, 2005.

Harrison, R. G. and Stephenson, D. B.: Empirical evidence for a nonlinear effect of galactic cosmic rays on clouds, P. R. Soc. A, 462, 1221-1233, 2006.

Harrison, R. G.: Cloud Formation and the Possible Significance of Charge for Atmospheric Condensation and Ice Nuclei, Space Sci. Rev., 94, 381-396, 2000.

Harrison, R. G. and Aplin, K. L.: Atmospheric condensation nuclei formation and high-energy radiation, J. Atmos. Sol.-Terr. Phy., 63, 1811-1819, 2001.
Hirsikko, A., Bergman, T., Laakso, L., Dal Maso, M., Riipinen, I., Hõrrak, U., and Kulmala, M.: Identification and Classification of the formation of intermediate ions measured in boreal forest, Atmos. Chem. Phys., 7, 201-210, 2007a.

Hirsikko, A., Yli-Juuti, T., Neiminen, T., Vartiainen, E., Laakso, L., Hussein, T., and Kulmala, M.: Indoor and outdoor air ions and aerosol particles in the urban atmosphere of Helsinki: characteristics, sources and formation, Boreal Environ. Res., 12, 295-310, 2007b.

Holland, P. M. and Castlemann Jr., A. W.: Thomson Equation Revisited in Light of Ion-Clustering Experiments, J. Phys. Chem., 86, 4181-4188, 1982.

Hoppel, W. A., Frick, G. M., and Fitzgerald, J. W.: Marine boundeary layer measurements of new particle formation and the effects nonprecipitating clouds have, J. Geophys. Res., 99, 14443 14459, 1994.

Hõrrak, U., Mirme, A., Salm, J., Tamm, E., and Tammet, H.: Air ion measurements as a source of information about atmospheric aerosols, Atmos. Res., 46, 233-242, 1998a.

Hõrrak, U., Salm, J., and Tammet, H.: Bursts of intermediate ions in atmospheric air, J. Geophys. Res., 103, 13 909-13915, doi:10.1029/97JD01570, 1998b.

Hõrrak, U., Aalto, P. P., Salm, J., Komsaare, K., Tammet, H., Mäkelä, J. M., Laakso, L., and Kulmala, M.: Variation and balance of positive air ion concentrations in a boreal forest, Atmos. Chem. Phys., 8, 655-675, 2008, http://www.atmos-chem-phys.net/8/655/2008/.

Iida, K., Stolzenburg, M., McMurry, P., Dunn, M. J., Smith, J. N., Eisele, F. and Keady, P.: Contribution of ion-induced nucleation to new particle formation: Methodology and its application to atmospheric observations in Boulder, Colorado, J. Geophys. Res. Atmos., 111, 23 201-23 216, doi:10.1029/2006JD007167, 2006.

Kathmann, S. M., Schenter, G. K., and Garrett, B. C.: Ion-Induced Nucleation: The Importance of Chemistry, Phys. Rev. Lett., 94, 2005.

Kathmann, S. M., Schenter, G. K., and Garrett, B. C.: Comment on Quantum Nature of the Sign Preference in Ion-Induced Nucleation, Phys. Rev. Lett., 98, 109603, doi:10.1103/PhysRevLett.98.109603, 2007.

Kazil, J., Lovejoy, E. R., Barth, M. C., and O'Brien, K.: Aerosol nucleation over oceans and the role of galactic cosmic rays, Atmos. Chem. Phys., 6, 4905-4924, 2006, http://www.atmos-chem-phys.net/6/4905/2006/.

Kerminen, V.-M., Anttila, T., Petäjä, T., Laakso, L., Gagné, S., Lehtinen, K. E. J., and Kulmala, M.: Charging state of the atmospheric nucleation mode: Implications for separating neutral and ion-induced nucleation, J. Geophys. Res. Atmos., 112, 21205, doi:10.1029/2007JD008649, 1-12, 2007.

Kiang, C. S. and Stauffer, D.: Chemical Nucleation Theory for Various Humidities and Pollutants, Faraday Symposium of the Chemical Society, 7, 26-33, 1973.

Kim, T. O., Adachi, M., Okuyama, K., and Seinfeld, J. H.: Experimental Measurement of Competitive Ion-Induced and Binary Homogeneous Nucelation in $\mathrm{SO}_{2} / \mathrm{H}_{2} \mathrm{O} / \mathrm{N}_{2}$ Mixtures, Aerosol Sci. Technol., 26, 527-543, 1997.

Kim, T. O., Ishida, T., Adachi, M., Okuyama, K., and Seinfeld, J. H.: Nanometer-Sized Particle Formation from $\mathrm{NH}_{3} / \mathrm{SO}_{2} / \mathrm{H}_{2} \mathrm{O} /$ Air Mixtures by Ionizing Irradiation, Aerosol Sci. Technol., 29, 111-125, 1998. 
Komppula, M., Vana, M., Kerminen, V.-M., Lihavainen, H., Viisanen, Y., Hõrrak, U., Komsaare, K., Tamm, E., Hirsikko, A., Laakso, L., and Kulmala, M.: Size distributions of atmospheric ions in the Baltic Sea region, Boreal Environ. Res., 12, 323-336, 2007.

Kulmala, M. and Tammet, H.: Finnish-Estonian air ion and aerosol workshops, Boreal Environ. Res., 12, 237-245, 2007.

Kulmala, M., Pirjola, L., and Mäkelä, J. M.: Stable sulphate clusters as a source of new atmospheric particles, Nature, 404, 66-69, 2000.

Kulmala, M., Laakso, L., Lehtinen, K. E. J., Riipinen, I., Dal Maso, M., Anttila, T., Kerminen, V.-M., Hõrrak, U., Vana, M., and Tammet, H.: Initial steps of aerosol growth, Atmos. Chem. Phys., 4, 2553-2560, 2004a.

Kulmala, M., Vehkamäki, H., Petäjä, T., Dal Maso, M., Lauri, A., Kerminin, V. M., Birmili, W., and McMurry, P. H.: Formation and growth rates of ultrafine atmospheric particles: a review of observations, J. Aerosol Sci., 35, 143-176, 2004b.

Kulmala, M., Lehtinen, K. E. J., and Laaksonen, A.: Cluster activation theory as an explanation of the linear dependence between formation rate of $3 \mathrm{~nm}$ particles and sulphuric acid concentration, Atmos. Chem. Phys., 6, 787-793, 2006, http://www.atmos-chem-phys.net/6/787/2006/.

Kulmala, M., Riipinen, I., Sipilä, M., Manninen, H. E., Petäjä, T., Junninen, H., Maso, M. D., Mordas, G., Mirme, A., Vana, M., Hirsikko, A., Laakso, L., Harrison, R. M., Hanson, I., Leung, C., Lehtinen, K. E. J., and Kerminen, V.-M.: Towards Direct Measurement of Atmospheric Nucleation, Science, 318, 89-92, 2007

Kurtén, T., Noppel, M., Vehkamäki, H., Salonen, M., and Kulmala, M.: Quantum chemical studies of hydrate formation of $\mathrm{H}_{2} \mathrm{SO}_{4}$ and $\mathrm{HSO}_{4}^{-}$, Boreal Environ. Res., 12, 431-453, 2007.

Laakso, L., Mäkelä, J. M., Pirjola, L., and Kulmala, M.: Model studies on ion-induced nucleation in the atmosphere, J. Geophys. Res. Atmos., 107, 4427-4445, doi:10.1029/2002JD002140, 2002.

Laakso, L., Anttila, T., Lehtinen, K. E. J., Aalto, P. P., Kulmala, M., Hõrrak, U., Paatero, J., Hanke, M., and Arnold, F.: Kinetic nucleation of ions in boreal forest particle formation events, Atmos. Chem. Phys., 4, 2353-2366, 2004a.

Laakso, L., Petäjä, T., Lehtinen, K. E. J., Kulmala, M., Paatero, J., Hõrrak, U., Tammet, H., and Joutsensaari, J.: Ion production rate in a boreal forest based on ion particle and radiation measurements, Atmos. Chem. Phys., 4, 1933-1943, 2004b.

Laakso, L., Gagné, S., Petäjä, T., Hirsikko, A., Aalto, P. P., Kulmala, M., and Kerminen, V.-M.: Detecting charging state of ultra-fine particles: instrumental development and ambient measurements, Atmos. Chem. Phys., 7, 1333-1345, 2007,

http://www.atmos-chem-phys.net/7/1333/2007/.

Lee, S.-H., Reeves, J. M., Wilson, J. C., Hunton, D. E., Viggiano, A. A., Miller, T. M., Ballenthin, J. O., and Lait, L. R.: Particle Formation by Ion Nucleation in the Upper Troposphere and Lower Stratosphere, Science, 301, 1886-1889, doi:10.1126/science.1087236, 2003.

Lihavainen, H., Komppula, M., Kerminen, V.-M., Järvinen, H., Viisanen, Y., Lehtinen, K., Vana, M., and Kulmala, M.: Size distributions of atmospheric ions inside clouds and in cloud-free air at a remote continental site, Boreal Environ. Res., 12, 337-344, 2007.
Loeb, L. B., Kip, A. F., and Einarsson, A. W.: On the Nature of Ionic Sign Preference in C. T. R. Wilson Cloud Chamber Condensation Experiments, J. Chem. Phys., 6, 264-273, 1938.

Lovejoy, E. R. and Curtius, J.: Cluster Ion Thermal Decomposition (II): Master Equation Modeling in the Low-Pressure Limit and Fall-Off Regions. Bond energies for $\mathrm{HSO}_{4}^{-}\left(\mathrm{H}_{2} \mathrm{SO}_{4}\right)_{\mathrm{x}}\left(\mathrm{HNO}_{3}\right)_{y}$, J. Phys. Chem. A, 105, 10 874-10 883, 2001.

Lovejoy, E. R., Curtius, J., and Froyd, K. D.: Atmospheric ioninduced nucleation of sulfuric acid and water, J. Geophys. Res. Atmos., 109, 8204-8214, doi:10.1029/2003JD004460, 2004.

Mäkelä, J. M., Aalto, P., Jokinen, V., Pohja, T., Nissinen, A., Palmroth, S., Markkanen, T., Seitsonen, K., Lihavainen, H., and Kulmala, M.: Observations of ultrafine aerosol particle formation and growth in boreal forest, Geophys. Res. Lett., 24, 1219-1222, doi:10.1029/97GL00920, 1997.

Marsh, N. and Svensmark, H.: Galactic cosmic ray and El NiñoSouthern Oscillation trends in International Satellite Cloud Climatology Project D2 low-cloud properties, J. Geophys. Res. Atmos., 108, 4195-4205, doi:10.1029/2001JD001264, 2003.

Megaw, W. J. and Wiffen, R. D.: The generation of condensation nuclei by ionising radiation, Pure Appl. Geophys., 50, 118-128, 1961.

Metnieks, A. L. and Pollak, L. W.: Instructions for use of photoelectric condensation nucleus counters, their care and maintenance together with calibration and auxiliary tables, Geophys. Bull., School of Cosmic Physics Dublin Inst. for Advanced Studies, 16, 1959.

Nadykto, A. B. and Yu, F.: Dipole Moment of Condensing Monomers: A New Parameter Controlling the Ion-Induced Nucleation, Phys. Rev. Lett., 93, 2004.

Nadykto, A. B., Al Natsheh, A., Yu, F., Mikkelsen, K. V., and Ruuskanen, J.: Quantum Nature of the Sign Preference in Ion-Induced Nucleation, Phys. Rev. Lett., 96, 125701, doi:10.1103/PhysRevLett.96.125701, 2006.

Nadykto, A. B., Al Natsheh, A., Mikkelsen, K. V., Yu, F., and Ruuskanen, J.: Comment on Quantum Nature of the Sign Preference in Ion-Induced Nucleation - Reply, Phys. Rev. Lett., 98 , 2007.

O’Dowd, C., McFiggans, G., Creasey, D. J., Pirjola, L., Hoell, C., Smith, M. H., Allan, B. J., Plane, J. M. C., Heard, D. E., Lee, J. D., Pilling, M. J., and Kulmala, M.: On the photochemical production of new particles in the coastal boundary layer, Geophys. Res. Lett., 26, 1707-1710, doi:10.1029/1999GL900335, 1999.

Rabeony, H. and Mirabel, P.: Experimental Study of Vapor Nucleation on Ions, J. Phys. Chem., 91, 1815-1818, 1987.

Raes, F. and Janssens, A.: Ion-induced Aerosol Formation in a $\mathrm{H}_{2} \mathrm{O}-\mathrm{H}_{2} \mathrm{SO}_{4}$ system-1. Extension of the Classical Theory and search for Experimental Evidence, J. Aerosol Sci., 16, 217-227, 1985.

Raes, F., Janssens, A., and Eggermont, G.: A synergism between ultraviolet and gamma radiation in producing aerosol particles from $\mathrm{SO}_{2}-\mathrm{H}_{2} \mathrm{SO}_{4}$ laden atmospheres, Atmos. Environ., 19, 1069-1073, 1985.

Reiss, H.: The Kinetics of Phase Transitions in Binary Systems, J. Chem. Phys., 18, 840-848, 1950

Seinfeld, J. H. and Pandis, S. N.: Atmospheric Chemistry and Physics: From Air Pollution to Climate Change, John Wiley \& Sons, 1998. 
Sorokin, A. and Arnold, F.: Laboratory study of cluster ions formation in $\mathrm{H}_{2} \mathrm{SO}_{4}-\mathrm{H}_{2} \mathrm{O}$ system: Implications for threshold concentration of gaseous $\mathrm{H}_{2} \mathrm{SO}_{4}$ and ion-induced nucleation kinetics, Atmos. Environ., 41, 3740-3747, 2007.

Sorokin, A., Arnold, F., and Wiedner, D.: Formation and growth of sulphuric acid-water cluster ions: Experiments, modelling, and implications for ion-induced aerosol formation, Atmos. Environ., 40, 2030-2045, 2006.

Svensmark, H. and Friis-Christensen, E.: Variation of cosmic ray flux and global cloud coverage - a missing link in solar-climate relationships, J. Atmos. Sol-Terr. Phy., 59, 1225-1232, 1997.

Svensmark, H., Pedersen, J. O. P., Marsh, N. D., Enghoff, M. B., and Uggerhøj, U. I.: Experimental evidence for the role of ions in particle nucleation under atmospheric conditions, P. R. Soc. A, 463, 385-396, 2007.

Tiitta, P., Miettinen, P., Vaattovaara, P., Laaksonen, A., Joutsensaari, J., Hirsikko, A., Aalto, P., and Kulmala, M.: Road-side measurements of aerosol and ion number size distributions: a comparison with remote site measurements, Boreal Environ. Res., 12, 311321, 2007.

Tinsley, B. A.: Influence of solar wind on the global electric circuit, and inferred effects on cloud microphysics, temperature, and dynamics in the troposphere, Space Sci. Rev., 94, 231-258, 2000.

Turco, R. P., Zhao, J.-X., and Yu, F.: A new source of tropospheric aerosols: Ion-ion recombination, Geophys. Res. Lett., 25, 635638, doi:10.1029/98GL00253, 1998.

Udelhofen, P. M. and Cess, R. D.: Cloud cover variations over the United States: An influence of cosmic rays or solar variability?, Geophys. Res. Lett., 28, 2617-2620, 2001.

Vana, M., Tamm, E., Hõrrak, U., Mirme, A., Tammet, H., Laakso, L., Aalto, P. P., and Kulmala, M.: Charging state of atmospheric nanoparticles during the nucleation burst events, Atmos. Res., 82, 536-546, 2006.

Vartiainen, E., Kulmala, M., Ehn, M., Hirsikko, A., Junninen, H., Petäjä, T., Sogacheva, L., Kuokka, S., Hillamo, R., Skorokhod, A., Belikov, I., Elansky, N., and Kerminen, V.-M.: Ion and particle number concentrations and size distributions along the TransSiberian railroad, Boreal Environ. Res., 12, 375-396, 2007.

Viggiano, A. A.: In situ mass spectrometry and ion chemistry in the stratosphere and troposphere, Mass Specrom. Rev., 12, 115-137, 1993.

Viisanen, Y., Kulmala, M., and Laaksonen, A.: Experiments on gasliquid nucleation of sulfuric acid and water, J. Chem. Phys., 107, 920-926, 1997.

Virkkula, A., Hirsikko, A., Vana, M., Aalto, P. P., Hillamo, R., and Kulmala, M.: Charged particle size distributions and analysis of particle formation events at the Finnish Antarctic research station Aboa, Boreal Environ. Res., 12, 397-408, 2007.

Vohra, K. G., Subba Ramu, M. C., and Muraleedharan, T. S.: An experimental study of the role of radon and its daughter products in the conversion of sulphur dioxide into aerosol particles in the atmosphere, Atmos. Environ., 18, 1653-1656, 1984.

Weber, R. J., Marti, J. J., McMurry, P. H., Eisele, F. L., Tanner, D. J., and Jefferson, A.: Measured atmospheric new particle formation rates: Implications for nucleation mechanisms, Chem. Eng. Commun., 151, 53-64, 1996.
Weber, R. J., Marti, J. J., McMurry, P. H., Eisele, F. L., Tanner, D. J., and Jefferson, A.: Measurements of new particle formation and ultrafine particle growth rates at a clean continental site, J. Geophys. Res., 102, 4375-4385, doi:10.1029/96JD03656, 1997.

Weber, R. J., McMurry, P. H., Mauldin, L., Tanner, D. J., Eisele, F. L., Brechtel, F. J., Kreidenweis, S. M., Kok, G. L., Schillawski, R. D., and Baumgardner, D.: A study of new particle formation and growth involving biogenic and trace gas species measured during ACE 1, J. Geophys. Res., 103, 16385-16396, doi:10.1029/97JD02465, 1998.

Weber, R. J., Chen, G., Davis, D. D., Mauldin III, R. L., Tanner, D. J., Eisele, F. L., Clarke, A. D., Thornton, D. C., and Bandy, A. R.: Measurements of enhanced $\mathrm{H}_{2} \mathrm{SO}_{4}$ and 3-4 nm particles near a frontal cloud during the First Aerosol Characterization Experiment (ACE 1), J. Geophys. Res., 106, 24 107-24 117, doi:10.1029/2000JD000109, 2001a.

Weber, R. J., Moore, K., Kapustin, V., Clarke, A., Mauldin, R. L., Kosciuch, E., Cantrell, C., Eisele, F., Anderson, B., and Thornhill, L.: Nucleation in the equatorial Pacific during PEM-Tropics B: Enhanced boundary layer $\mathrm{H}_{2} \mathrm{SO}_{4}$ with no particle nucleation, J. Geophys. Res., 106, 32 767-32 776, doi:10.1029/2001JD90025, 2001b

Wilhelm, S., Eichkorn, S., Wiedner, D., Pirjola, L., and Arnold, F.: Ion-induced aerosol formation: new insights from laboratory measurements of mixed cluster ions $\mathrm{HSO}_{4}^{-}\left(\mathrm{H}_{2} \mathrm{SO}_{4}\right)_{\mathrm{a}}\left(\mathrm{H}_{2} \mathrm{O}\right)_{\mathrm{W}}$ and $\mathrm{H}^{+}\left(\mathrm{H}_{2} \mathrm{SO}_{4}\right)_{\mathrm{a}}\left(\mathrm{H}_{2} \mathrm{O}\right)_{\mathrm{w}}$, Atmos. Environ., 38, 1735-1744, 2004.

Wilson, C. T. R.: The Effect of Röntgen's Rays on Cloudy Condensation, P. R. Soc. London, 59, 338-339, 1895.

Wilson, C. T. R.: On the Condensation Nuclei Produced in Gases by the Action or Röntgen Rays, Uranium Rays, Ultra-Violet Light and Other Agents, Philos. T. R. Soc. Lond., Series A, 192, 403453, 1899.

Winkler, P., Steiner, G., Vrtala, A., Vehkamäki, H., Noppel, M., Lehtinen, K. E. J., Reischl, G. P., Wagner, P., and Kulmala, M.: Heterogeneous Nucleation Experiments Bridging the Scale from Molecular Ion Clusters to Nanoparticles, Science, 319, 1374 1377, 2008.

Wyslouzil, B. E., Seinfeld, J. H., Flagan, R. C., and Okuyama, K.: Binary nucleation in acid-water systems. II. Sulfuric acid-water and a comparison with methanesulfonic acid-water, J. Chem. Phys., 94, 6842-6850, 1991.

Yu, F.: Modified Kelvin-Thomson equation considering ion-dipole interaction: Comparison with observed ion-clustering enthalpies and entropies, J. Chem. Phys., 122, 1-8, 2005.

Yu, F.: From molecular clusters to nanoparticles: second-generation ion-mediated nucleation model, Atmos. Chem. Phys., 6, 51935211, 2006a.

Yu, F.: From molecular clusters to nanoparticles: second-generation ion-mediated nucleation model, Atmos. Chem. Phys. Discuss., 6, 3049-3092, 2006b.

Yu, F. and Turco, R. P.: The formation and evolution of aerosols in stratospheric aircraft plumes: Numerical simulations and comparisons with observations, J. Geophys. Res., 103, $25915-$ 25 934, doi10.1029/98JD02453, 1998. 
Yu, F. and Turco, R. P.: Evolution of aircraft-generated volatile particles in the far wake regime: Potential contributions to ambient CCN/IN, Geophys. Res. Lett., 26, 1703-1706, 1999.

Yu, F. and Turco, R. P.: Ultrafine aerosol formation via ionmediated nucleation, Geophys. Res. Lett., 27, 883-886, 2000.

Yu, F. and Turco, R. P.: From molecular clusters to nanoparticles: Role of ambient ionization in tropospheric aerosol formation, J. Geophys. Res., 106, 4797-4814, 2001.

Yu, F., Wang, Z., Luo, G., and Turco, R. P.: Interactive comment on "Ion-mediate nucleation as an important global source of tropospheric aerosols", Atmos. Chem. Phys. Discuss., 7, S6602S6608, 2007a.
Yu, F., Wang, Z., Luo, G., and Turco, R. P.: Interactive comment on Ion-mediated nucleation as an important global source of tropospheric aerosols, Atmos. Chem. Phys. Discuss., 7, S6754-S6766, 2007b.

Yu, F., Wang, Z., Luo, G., and Turco, R.: Ion-mediated nucleation as an important global source of tropospheric aerosols, Atmos. Chem. Phys., 8, 2537-2554, 2008, http://www.atmos-chem-phys.net/8/2537/2008/.

Yue, G. K.: On the Characteristics of Sulfate Aerosols formed in the Presence of Ion Sources, J. Aerosol Sci., 10, 387-393, 1979. 